\title{
Análisis de las políticas públicas para paliar la pobreza infantil en España durante la Gran Recesión y la Crisis del COVID-19
}

\author{
Enrique Solé León ${ }^{1}$
}

La Gran Recesión es el nombre que recibe el periodo de crisis económica mundial cuyos efectos se notaron en España de 2008 a 2014. Sus consecuencias fueron terribles a nivel social y económico; prueba de ello es que, entre esos dos años, el PIB del país se redujo casi un 7\% (INE, 2019).

Más de una década después, en 2020, la Organización Mundial de la Salud (OMS) declaró como pandemia una nueva enfermedad provocada por un virus de la familia de los coronavirus, el COVID-19, que surgió en la provincia china de Wuhan en diciembre del año anterior (OMS, 2020). La llegada de esta pandemia a España hizo que el Gobierno decretara el Estado de alarma implementando medidas de contención para evitar la propagación de la enfermedad. Este parón social y económico hizo que el país pusiera fin a un periodo de crecimiento económico iniciado seis años antes y que el Gobierno previera una caída del 9,2\% en el producto interior bruto para ese mismo año (Ministerio de Hacienda, 2020), más que en ningún año durante la Gran Recesión.

En este contexto, este texto quiere responder a una pregunta: ¿Qué políticas públicas siguió el Gobierno de España durante la Gran Recesión y durante la Crisis del COVID-19 para paliar la pobreza infantil?

Para responder a esta pregunta, esta investigación hace un análisis de políticas públicas en el que se estudian algunos de los pasos que indica Manuel Tamayo (1997) para el proceso de construcción de las políticas públicas. En primer lugar, se trata la identificación y definición del problema, le sigue una formulación de las alternativas de solución y, por último, la implantación de la alternativa. Faltarían fases importantes de este ciclo como la evaluación de las políticas, pero la inmediatez y actualidad de la Crisis del COVID-19 no permite todavía conocer los resultados de las mismas. Además, este mismo autor indica que no tienen por qué darse todas las fases ni en ese orden en todas las políticas. Así, en este texto nos centraremos en estas tres fases.

\section{Identificación y definición del problema de la pobreza infantil en la Gran Recesión y en la Crisis del COVID-19}

En abril de 2009, al poco de comenzar la Gran Recesión, el Consejo de la Unión Europea incluyó a España en un proceso por déficit excesivo, lo que comprometía fuertemente al país (Decisión del Consejo 2009/417/CE, 2009). Además, tal como se puede ver en el gráfico 1, el paro y los problemas de índole económica escalaron de forma espectacular entre las principales preocupaciones de los españoles en el periodo 2007-2012. En este periodo, los problemas sociales, entre los que se encuentra la pobreza, solo fueron nombrados por una minoría de los encuestados por el Centro de Investigaciones Sociológicas (CIS).

Desde esta perspectiva, no parece que la pobreza infantil fuera un problema público. Sin embargo, si atendemos a los datos, un 30,5\% de los niños y niñas menores de 16 años se encontraba en riesgo de pobreza y/o exclusión social en 2008, llegando al final de la Gran Recesión, en 2014, al máximo de 35,3\% (INE, 2020). Aunque alarmante, este no fue un incremento significativo en un país donde el riesgo de pobreza suele situarse entre los más altos de Europa (Eurostat, 2020).

Así, durante la Gran Recesión el problema de la pobreza infantil se definió bajo una enorme presión de control del gasto público, supeditado a otras políticas consideradas más urgentes en aquel momento como el desempleo y sin una consciencia social fuerte sobre su importancia. 


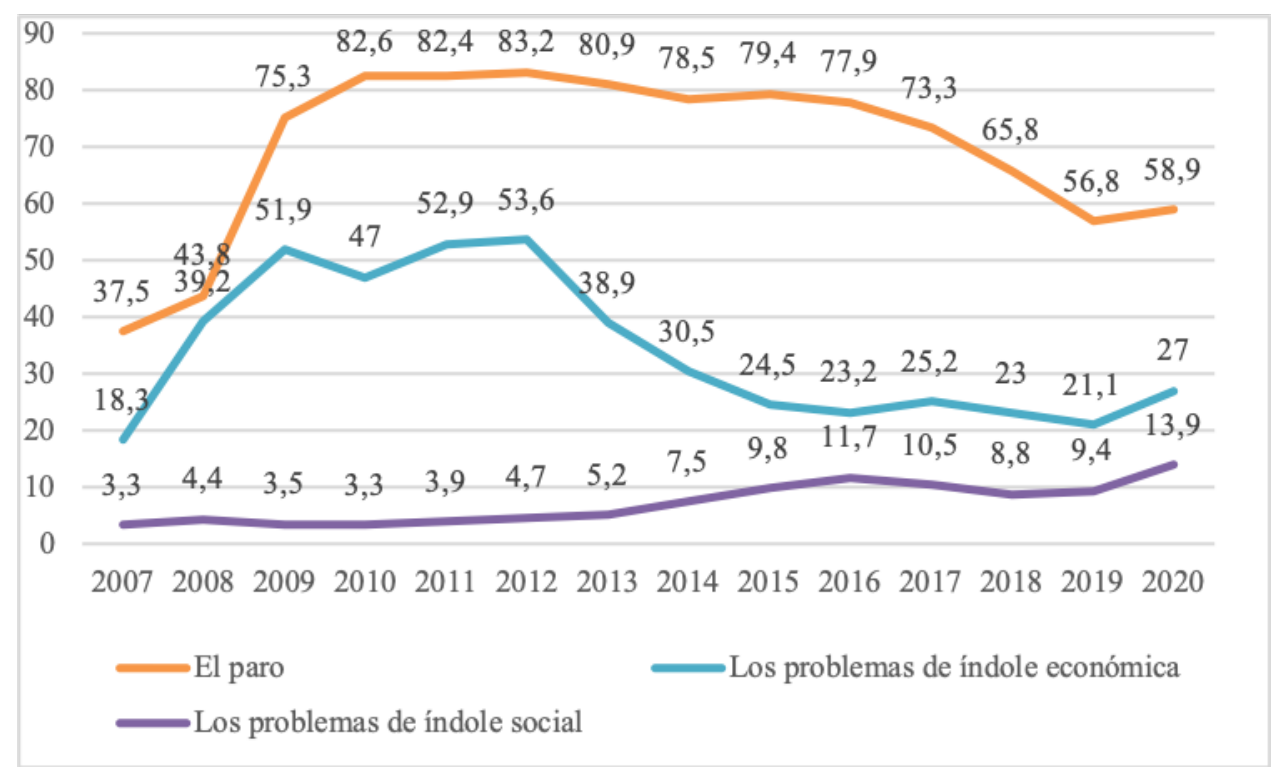

Gráfico 1. Porcentaje de encuestados que consideraban los siguientes temas seleccionados como principales problemas de España en el mes de enero. Fuente: Elaboración propia a base de datos del CIS (2007-2020).

Por otra parte, durante la Crisis del COVID-19, España ya había salido del proceso de control del déficit desde junio de 2019, lo que disminuía la presión por controlar el gasto público (Decisión (UE) del Consejo 2019/1001, 2019). No obstante, la tasa de riesgo de pobreza para las personas menores de 16 años se situó en el 29,9\% en 2018, casi alcanzando al mínimo histórico (INE, 2020).

Esto parecería dar a entender que los españoles no deberían preocuparse tanto por este asunto, aunque las encuestas del CIS reflejan un ligero repunte en la preocupación por problemas sociales, quizás debido a una mayor conciencia social de los mismos. Pese a ello, estos problemas no eran de los más señalados en los barómetros.

\section{Formulación de alternativas de políticas contra la pobreza infantil en la Gran Recesión y en la Crisis del COVID-19}

Pau Marí-Klose y Marga Marí-Klose (2012) diferencian tres tipos de políticas públicas para combatir la pobreza infantil. En primer lugar, transferencias públicas a familias con hijos dependientes, bien sean directas o a través de deducciones fiscales. Le siguen la prestación de servicios gratuitos o a precios asequibles de educación y sanidad principalmente. En tercer lugar, se encuentra la activación laboral de los progenitores desempleados en caso de estarlo.

Tras ver la definición del problema de la pobreza infantil durante la Gran Recesión, el Gobierno no consideró las dos primeras opciones viables, ya que comprometerían los objetivos de déficit. Así, tanto por la opinión de los españoles (gráfico 1) como por las recomendaciones de la Comisión Europea (2012), parecía claro que la decisión política más conveniente era dar prioridad a la política de empleo.

Sin embargo, la Crisis del COVID-19 tenía un origen distinto a la Gran Recesión. En esta ocasión, las políticas de transferencias públicas y las de acceso a la sanidad y educación podían valorarse como alternativas viables debido a la urgencia que requería la intervención pública. En el caso concreto de la educación, numerosos alumnos se habían quedado sin la posibilidad de continuar con sus estudios presenciales, poniéndose de manifiesto la brecha digital existente en la sociedad. De 1.350 familias vulnerables atendidas por Save the Children, un 48,7\% no disponían de equipos electrónicos o acceso a internet, lo que imposibilitaba el seguimiento de estas clases a distancia (Save the Children, 2020).

Por el contrario, no se implementaron medidas de activación laboral sino de protección a los desempleados (Ministerio de Derechos Sociales y Agenda 2030, 2020). Debido a lo repentino de los acontecimientos, el Gobierno previó una destrucción de empleo del 9,7\% y un incremento de la tasa de paro del 19\% para 2020 (Gobierno de España, 2020), así que se valoraron primero medidas de protección al desempleo y evitar la destrucción de puestos antes que de reactivación laboral.

\section{Implantación de las alternativas seleccionadas}

Al no haber sido las transferencias públicas una de las políticas seleccionadas, se puede ver cómo entre 2007 y 2013 la prestación por hijo a cargo no representaba más de 24 euros mensuales. Además, la cuantía media de estas desgravaciones pasó de $1.857 €$ en 2007 a $1.111 €$ en 2013 (Fundación FOESSA, 2019). Igualmente, durante la Gran 
Recesión, la sanidad y la educación sufrieron importantes recortes presupuestarios con la justificación de reducir la deuda y cumplir con los objetivos de déficit.

Así, de las tres políticas arriba indicadas para paliar la pobreza infantil, el Gobierno dio más importancia a la política de empleo. De esta forma, aprobó el Real Decreto-ley 3/2012, de medidas urgentes para la reforma del mercado laboral, una reforma controvertida cuyos partidarios afirman que fomentaba la flexibilidad laboral (Sanromà, 2012), pero cuyos detractores sostienen que aumentaba la precariedad (UGT, 2019).

De otra parte, durante la Crisis del COVID-19, finalmente no se decidió ninguna medida que implicara una transferencia monetaria a las familias, sino que directamente se invirtió en servicios gratuitos de educación. Por ejemplo, el Gobierno central constituyó una dotación adicional de 25 millones de euros en becas comedor (Ministerio de Derechos Sociales y Agenda 2030, 2020) o facilitó 20.000 líneas móviles para continuar su formación de forma telemática, aunque solo a alumnos de Bachillerato y Formación Profesional, dejando a niños y niñas por debajo de ese nivel educativo sin acceso al seguimiento online de las clases (Ministerio de Educación, 2020). Las políticas de sanidad estuvieron centradas en paliar la expansión de la enfermedad, sin efectos distintos en la infancia con respecto al resto de la sociedad.

Con respecto a la activación laboral de los progenitores, lo reciente de la Crisis del COVID-19 no permite saber qué medidas de activación laboral implementará el Gobierno de España en un futuro próximo, ya que, como se ha indicado previamente, se dio prioridad a medidas de protección al desempleo.

\section{Conclusiones}

Tanto durante la Gran Recesión como durante la Crisis del COVID-19, el Gobierno de España no tuvo la presión ciudadana de que la pobreza infantil fuera un problema acuciante, a pesar de las alarmantes tasas de riesgo de pobreza entre menores de 16 años.

Por este motivo, durante la Gran Recesión el Gobierno apenas prestó atención a este asunto, centrándose en la disminución de la tasa de paro, medida que centraba la agenda política y que de forma indirecta también reducía los niveles de pobreza infantil.

Sin embargo, durante la Crisis del COVID-19, el Gobierno prefirió realizar una inversión extra en políticas educativas extraordinarias como becas comedor o ayudas puntuales para el estudio a distancia.

Cada una de las políticas no hacían sino responder a las necesidades de la crisis que intentaban paliar. En el caso de la Gran Recesión, se requería una urgente reactivación laboral de gran parte de la población, lo que también mejoraría la situación de pobreza infantil de muchos niños y niñas con familiares en paro, mientras que la del COVID-19 exigía una actuación rápida ante una emergencia sanitaria que no desvinculara a los niños y niñas de sus estudios.

\section{Referencias bibliográficas}

Centro de Investigaciones Sociológicas (2007-2020). Barómetro de enero (en línea). http://www.cis.es/cis/opencm/ES/2_bancodatos/estudios/anual.jsp, acceso 5 de junio de 2020.

Comisión Europea (2012). Evaluación del programa nacional de reforma y del programa de estabilidad de España para 2012 que acompaña al documento recomendación del Consejo (en línea). https://ec.europa.eu/info/sites/info/files/file_import/ swd2012_spain_es_0.pdf, acceso 14 de mayo de 2020.

Decisión del Consejo 2009/417/CE (2009), de 27 de abril, sobre la existencia de un déficit excesivo en España. Diario Oficial de la Unión Europea L135/25, 30 de mayo de 2009.

Decisión (UE) del Consejo 2019/1001 (2019), de 14 de junio, por la que se deroga la Decisión 2009/417/CE sobre la existencia de un déficit excesivo en España. Diario Oficial de la Unión Europea L163/59, 20 de junio de 2019.

Eurostat (2020). People at risk of poverty or social exclusion (en línea). https://ec.europa.eu/eurostat/statistics-explained/index. php/People_at_risk_of_poverty_or_social_exclusion, acceso el 16 de mayo de 2020

Fundación FOESSA (2019). VIII Informe sobre Exclusión y Desarrollo Social en España (en línea). https://caritas-web.s3.amazonaws.com/main-files/uploads/sites/16/2019/05/Informe-FOESSA-2019-completo.pdf, acceso 9 de mayo de 2020.

Gobierno de España (2020), Actualización del programa de estabilidad 2020 (en línea). https://www.hacienda.gob.es/CDI/Programas\%20de\%20Estabilidad/Programa_de_Estabilidad_2020-2021.pdf, consultado el 15 de mayo de 2020.

INE (2019). PIB y PIB per cápita. Serie 2000-2018 (en línea). https://www.ine.es/dyngs/INEbase/es/operacion.htm?c=Estadistica_C\&cid=1254736167628\&menu=resultados\&idp=1254735576581\#!tabs-1254736158133, acceso 16 de mayo de 2020 .

INE (2020). Riesgo de pobreza y/o exclusión social (estrategia Europa 2020). Indicador AROPE (en línea). https://www.ine.es/ jaxiT3/Datos.htm?t=11201\#!tabs-tabla, acceso 8 de mayo 2020.

Marí-Klose, P., Marí-Klose, M. (2012). Crisi i pobresa infantil a Catalunya. En Docs infancia a Catalunya. UNICEF, Comité Catalunya.

Ministerio de Derechos Sociales y Agenda 2030 (2020). Guía de facilitación de acceso a las medidas (en línea). https://www. mscbs.gob.es/ssi/covid19/guia.htm, consultado el 16 de mayo de 2020. 
Ministerio de Educación (2020). El Ministerio de Educación y Formación Profesional, Telefónica, Cisco e IBM facilitan la continuidad educativa de los estudiantes de Bachillerato y FP (en línea). https://www.educacionyfp.gob.es/prensa/actualidad/2020/03/20200330-tarjetasdatos.html, consultado el 16 de mayo de 2020 .

Ministerio de Hacienda (2020). Programa Nacional de Reformas (en línea). https://www.hacienda.gob.es/CDI/ProgramaNacionaldeReformas/PNR_2020.pdf, acceso 7 de mayo de 2020.

OMS (2020). Preguntas y respuestas sobre la enfermedad por coronavirus (COVID-19) (en línea) https://www.who.int/es/emergencies/diseases/novel-coronavirus-2019/advice-for-public/q-a-coronaviruses, acceso 7 de mayo de 2020.

Sanromà, E. (2012). El mercado de trabajo español en la crisis económica (2008-2012): desempleo y reforma laboral. Revista de Estudios Empresariales. Segunda Época. №2 (2012), 29-57.

Save the Children (2020). A tu lado, qué nos cuentan las familias (en línea). https://www.savethechildren.es/sites/default/files/2020-03/informesavethechildrenatulado.pdf, acceso 15 de mayo de 2020.

Tamayo, M. (1997). El análisis de las políticas públicas. En R. Bañón, E. Carrillo (comps.), La nueva Administración Pública (pp. 281-312). Madrid: Alianza Editorial.

UGT (2019). Los daños de la reforma laboral de 2012 (en línea). https://www.ugt.es/sites/default/files/danyos-de-la-reformalaboral-de-2012-ugt_0.pdf, acceso 15 de mayo de 2020. 